УДК 634.45:631.526.32 (470.67)

https://doi.org/10.18619/2072-9146-2019-3-116-120

Рындин А.B

Загиров Н.Г.

Ибрагимов Н̈.А.

Федеральное государственное бюджетное научное учреждение

«Всероссийский научно-исследовательский институт цветоводства и субтропических культур"

Россия, г.Сочи

E-mail: subplod@mail.ru; nadir_dag@mail.ru

Ключевые слова: хурма восточная, интродуцированные сорта, надземная система, масса плодов, урожайность, качество плодов.

Конфоликт интересов: Авторы заявляют об отсутствии конффликта интересов.

\section{Для цитирования: Рындин А.В., Загиров Н.Г. .,} ИбраГИМОВ Н.А. БИОЛОГИЧЕСКАЯ ОЦЕНКА ИНТРО ДУЦИРОВАННЫХ СОРТОВ ХУРМЫ ВОСТОЧНОЙ В СУХИХ СУБТРОПИКАХ ЮЖКНОГО ДАГЕСТАНА

Овощи России. 2019;(3):116-120

https://doi.org/10.18619/2072-9146-2019-3-116-120

Поступила в редакцию: 27.03.2019

Опубликована: 25.06 .2019

Ryndin A.V.

Zagirov N.G.,

lbragimov N.A.

Federal State Budgetary Scientific Institution «Russian Research Institute of Floriculture and

Subtropical Crops,

Russia, c. Sochi

E-mail: subplod@mail.ru; nadir_dag@mail.ru

Keywords: eastern persimmon, introduced varieties elevated system, mass of fruits, crop of trees, quality of fruits.

Conflict of interest: The authors declare no conflict of interest.

For citation: Ryndin A.V., Zagirov N.G., Ibragimov N.A. BIOLOGICAL ASSESSMENT OF THE INTRODUCED VARIETIES OF EASTERN PERSIMMON IN THE DRY SUBTROPICS OF SOUTHERN DAGESTAN. Vegetable crops of Russia. 2019:(3):116-120 (In Russ.)

htps://doi.org/10.18619/2072-9146-2019-3-116-120

Received: 27.03.2019

Accepted: 25.06.2019
БИОЛОГИЧЕСКАЯ ОЦЕНКА ИНТРОДУЦИРОВАННЫХ СОРТОВ ХУРМЫ ВОСТОЧНОЙ В СУХИХ

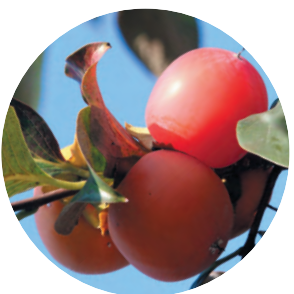

Целью исследований является изучение особенностей роста, развития и биохимического состава интродуцированных сортов хурмы восточной в условиях Южного Дагестана. Исследования в 2015-2018 годах проводили с применением общепринятых программ и классических методик сортоизучения и селекционных исследований. В результате работы изучены биологические особенности прохождения фенологических фаз интродуцированных сортов хурмы восточной конкретной территории для оптимизации размещения насаждений в промышленных плантациях и крестьянских хозяйствах. Предложены сорта хурмы, характеризующиеся ценными хозяйственно-биологическими признаками и свойствами с целью повышения урожайности. В условиях Южного Дагестана наибольшую высоту дерева имеет сорт Хачиа (4,74 м), диаметр кроны - сорт Джиро (4,26 м), а окружность штамба - сорт Хачиа (31,7 см). По средней массе плодов, продуктивности деревьев и урожайности с 1 га выделяется сорт хурмы восточной Хиакуме (317,2 г; 58,6 кг и 293,0 ц/га соответственно). Произведен биохимический анализ плодов основного сортимента плодов хурмы восточной, который показал, что по содержанию сухого вещества, сумме сахаров и витамина С выделяется сорт Хачиа (19,3\%, 13,6\% и 46,5 мг\% соответственно).

\title{
BIOLOGICAL ASSESSMENT OF THE INTRODUCED VARIETIES OF EASTERN PERSIMMON IN THE DRY SUBTROPICS OF SOUTHERN DAGESTAN
}

The aim of the research is to study the characteristics of growth, development and biochemical composition of the introduced varieties of eastern persimmon in the conditions of Southern Dagestan. Long-term studies for 2015-2018 were carried out with the use of generally accepted programs and classical methods of sorting and selection studies. As a result, the biological features of the passage of phenological phases of development of introduced varieties of persimmon eastern specific territory were studied to optimize plantings in industrial plantations and peasant farms, persimmon varieties were proposed that are characterized by valuable economic and biological characteristics and properties with the aim of increasing yields, where the fruit harvest from 1 tree and the yield from 1 ha is allocated the East Hiakume persimmon variety (317.2 g; $58.6 \mathrm{~kg}$ and $293.0 \mathrm{c} / \mathrm{ha}$ ). According to the peculiarities of growth and development in cultivation in the conditions of Southern Dagestan, it was found that the highest height of the tree is the Hachia variety (4.74), the crown diameter the Giro variety (4.26), and the trunk circle the Hachia variety $(31.7 \mathrm{~cm})$. A biochemical analysis of the fruits of the main assortment of Eastern persimmon fruits was performed, which showed that the Hachia variety was distinguished by the dry matter content, the amount of sugars and vitamin C (19.3\%, 13.6\% and $46.5 \mathrm{mg} \%$, respectively). 


\section{Введение}

Ооздание и возделывание экономически целесообразно-

гг и экологически безопасного плодового сада, в том числе и субтропического направления, особенно актуально при рыночной экономике [16]. Особый интерес в этом направлении представляет южная часть равнинной зоны Дагестана (приморская низменность), которая тянется узкой полосой вдоль Каспийского моря от Махачкалы до границы Республики Азербайджан, где расположены Дербентский, Магарамкентский и С.Стальский районы, которые входят в северную часть сухого субтропического пояса [4]. Рейтинги интегральной оценки пригодности земель служат индикатором оптимального фрактического размещения субтропических садов в Республике Дагестан. Конечно же низкий рейтинг пригодности не свидетельствует о том, что возделывание субтропических культур практически невозможно, он лишь отражает относительную затратность возделывания [5].

Одной из экономически и хозяйственно полезных культур региона является хурма восточная. Исследованиями различных авторов, проведенных с культурой, показано, что сорта Hiakume (Хиакуме, народное название - Королек), Насhia (Хачиа, Бычье сердце, Буденовка), Djiro (Джиро, Яблочное), Seedles, Zenji-Maru (Шоколадная), используемого в качестве опылителя, отличаются высокими хозяйственно ценными признаками [17]. Основными показателями роста и развития растения выделяют диаметр штамба и суммарный прирост побегов [18]. Установлено, что вегетация надземной системы хурмы восточной начинается в конце марта одновременно с другими семечковыми, а цветет на 20-22 суток позже яблони и груши. Продолжительность цветения составляет 7-9 суток (иногда до 15 суток). Цветение у различных сортов происходит не одновременно, но конец цветения почти совпадает. Самый короткий период цветения имеет сорт Хачиа, самый длительный - Хиакуме [2]. По урожайности и размерам плодов также выделяются эти сорта, которые на 6-10 год после посадки дают в среднем 304,6-355,6 ц/га (схема посадки 5х3 м) [14].

Проведенные исследования биохимических показателей свежих плодов хурмы восточной показали, что они зависят от сортовых особенностей, а также сильно подвержены значительной изменчивости под влиянием различных факторов внешней среды: условий возделывания, метеорологических особенностей, приемов агротехники.

Плоды всех сортов хурмы восточной отличаются высоким содержанием сахаров, однако содержание сахаров и кислоты в плодах хурмы восточной в период съемной зрелости у различных сортов разное. В условиях Южного Дагестана больше сахара содержится в плодах сорта Хачиа (13,57\%), меньше - у сорта Джиро (8,71\%). При благоприятных условиях в плодах хурмы содержание сахаров может достичь 25\%, при сушке содержание сахара значительно повышается и достигает свыше 55\%. Общие сахара в плодах хурмы представлены только редуцированными, в которых преобладает фрруктоза [16]. Кислотность плодов хурмы низкая - 0,1\%. В плодах также содержатся витамины C, Р, В, каротин, органическое железо [13]. В зависимости от погодных условий года плоды содержат от 30,11 до 49,7 мг\% витамина С [11]. Содержание минеральных веществ (зольность) в плодах хурмы колеблется в пределах 0,36-0,67\%. В состав зольных элементов входят многие полезные для организма микроэлементы [3]. По лежкости плодов самыми лучшими оказались плоды сортов Зенджи Мару и Джиро, менее - Хиакуме и Хачиа $[6,7,8,9]$.

Цель исследований - изучить биологические особенности роста, развития и плодоношения крупноплодных сортов хурмы восточной в современных климатических условиях, а также сделать их хозяйственную оценку с перспективой внедрения в сельскохозяйственное производство Южного Дагестана.

Объектами исследования служили сорта хурмы Хачиа (Hachia) (рис.1) - среднеспелый терпкий сорт японского происхождения, известен в народе как «Бычье сердце» или «Буденовка", районирован в Краснодарском крае и Дагестане повсеместно; Хиакуме (Hiakume) (рис.2) - среднеспелый варьирующий сорт японского происхождения, известен под названием «Королек», районирован в Дагестане и

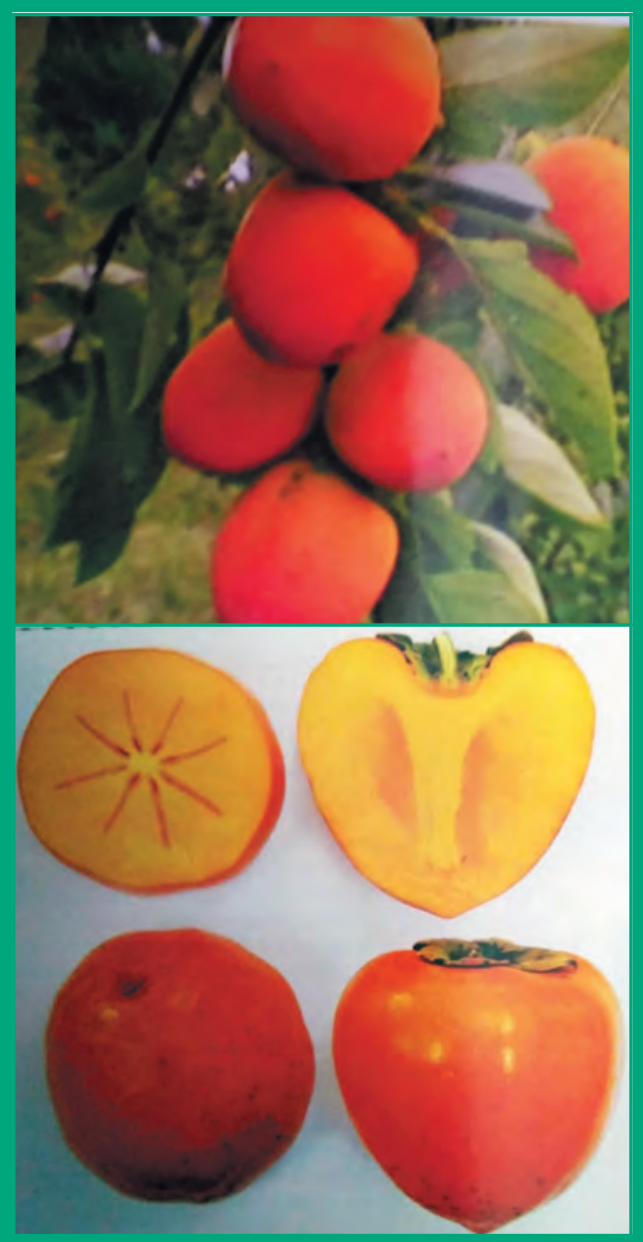

Рис. 1. Плоды хурмы восточной сорта Хачиа.

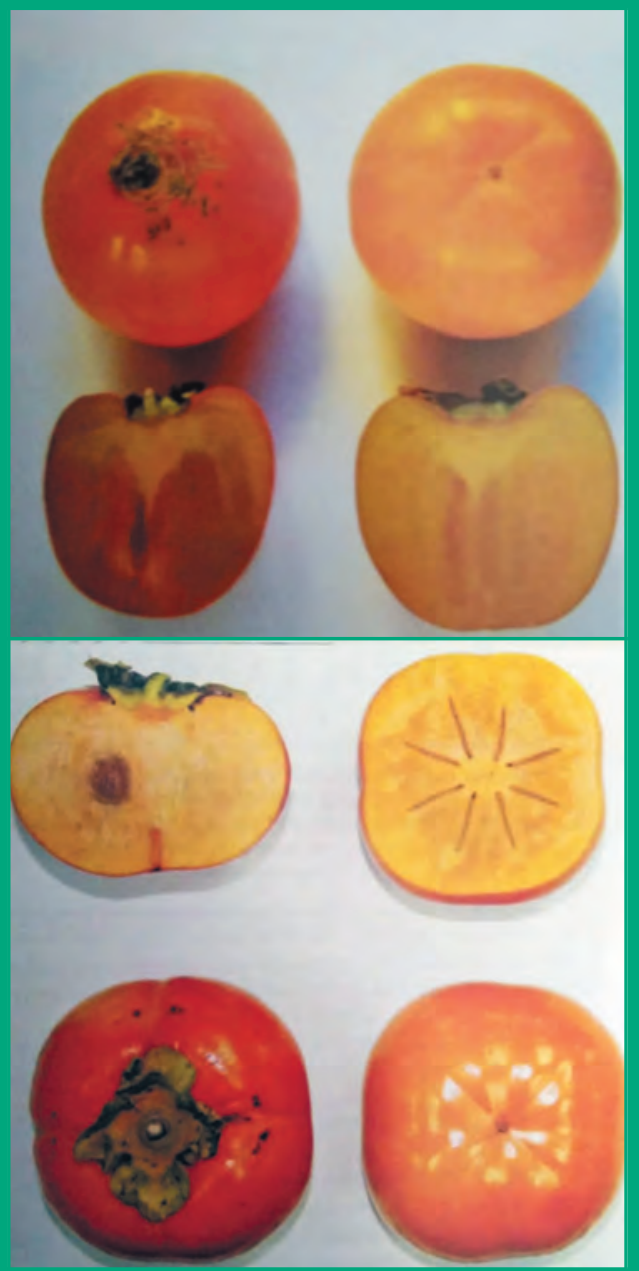

Рис. 2. Плоды хурмы восточной сортов Хиакуме и Джиро. 
Краснодарском крае; Джиро (Djiro) (рис.2) - позднеспелый нетерпкий сорт, под этим названием объединены два сорта «Превосходный» и «Чинебули», как идентичные в помологическом отношении, районирован в Дагестане и Краснодарском крае $[15,17]$.

\section{Методы исследований}

Исследования проводили в 2015-2018 годах в интенсивном саду научно-экспериментального полигона в селении Ходжа-казмаляр Магарамкентского района Республики Дагестан. Опытный участок расположен в южной равнинной подзоне. Эта зона в пределах рек Самур и Гюльгерычай занимает около 8 тыс. га. В климатическом отношении территория составляет одну зону с Хачмасским районом Азербайджана, характеризуется как умеренно теплая, полусухая. Испаряемость, как признак засушливости в дельте рек Самур и Гюльгерычай, достигает 800 мм, что в 2 раза превышает сумму выпадающих осадков. Все это характеризует климат как особо засушливый.

Агроэкологические возможности района научно-экспериментального полигона за 2015-2018 годы изучались и обобщались в сотрудничестве с Дагестанским центром по гидрометеорологии и мониторингу окружающей среды. Среднегодовая температура за 2015-2018 годы составила $14,4^{\circ} \mathrm{C}$; осадки - около 352 мм, влажность воздуха достигала 71\%; продолжительность безморозного периода по годам исследований варьировала от 336 до 358 суток. По данным метеостанции «Дербент» наибольший абсолютный максимум за 2015 год был установлен в августе $\left(36,5^{\circ} \mathrm{C}\right)$, за 2018 год в июле $\left(37,4^{\circ} \mathrm{C}\right)$, а среднегодовой за 2015-2018 годы составил $30,7^{\circ} \mathrm{C}$.

Схема размещения деревьев $5 \times 4$ м. Формировка - разреженно-ярусная, высота ограничена до 4 м. Площадь делянки

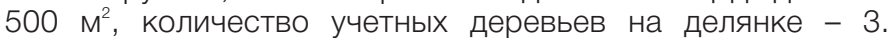

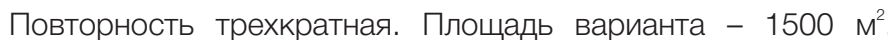
Количество учетных деревьев в варианте - 9. Общая площадь опытного сада - 1,2 га. Сад 2006 года посадки.

При закладке опыта придерживались программы и методики исследований, принятых в научных учреждениях по садоводству и описанных в литературе $[1,12,19]$.

На экспериментальном участке в соответствии с требованиями опытного дела выдерживался принцип единственного логического различия, заключающегося в сохранении в вариантах равенства условий внешней среды и других фракторов за исключением изучаемого.

Исследования биохимического состава плодов проводили общеизвестными стандартизированными методами в научноисследовательской лаборатории ФГБОУ ВО «Дагестанский государственный технический университет», технологический факультет, кафедра технологии пищевых производств общественного питания и товароведения.

\section{Результаты и их обсуждение}

Изучение сроков прохождения фенофаз в зависимости от сортов хурмы восточной показало, что за годы наблюдений существенного различия в наступлении фенологических фаз не отмечено. Набухание цветочных почек сортов проходило с 10 по 20 апреля в среднем за 2015-2018 годы, а распускание цветочных почек проходило в мае - с 15 по 25 число. Созревание плодов сортов хурмы восточной наблюдалось с 25 октября по 20 ноября. За годы исследований гибели цветочных почек особо не констатировали, цветение проходило стабильно. Данные сорта относительно устойчивы в этой подзоне к зимним морозам, выдерживают кратковременные морозы до $-21^{\circ} \mathrm{C}$.

Формирование деревьев хурмы проводили с первого года посадки до 5-6 летнего возраста по разреженно-ярусной форме. В дальнейшем при изучении роста и развития над-

Таблица 1. Рост и развитие надземной системы сортов хурмы восточной в условиях Дагестана за 2015-2018 годы Table 1. Growth and development of the elevated system of Eastern persimmon varieties in Dagestan conditions for 2015-2018

\begin{tabular}{|c|c|c|c|c|c|}
\hline \multirow{2}{*}{ Варианты } & \multicolumn{5}{|c|}{ Годы исследований } \\
\hline & 2015 & 2016 & 2017 & 2018 & 2015-2018 \\
\hline \multicolumn{6}{|c|}{ Высота дерева, м } \\
\hline Хачиа (K) & 4,40 & 4,64 & 4,85 & 5,06 & 4,74 \\
\hline Хиакуме & 3,49 & 3,71 & 4,15 & 4,48 & 3,96 \\
\hline Джиро & 3,92 & 4,24 & 4,61 & 4,90 & 4,42 \\
\hline $\mathrm{HCP}_{05}$ & 0,07 & 0,19 & 0,25 & 0,23 & 0,07 \\
\hline \multicolumn{6}{|c|}{ Диаметр кроны, м } \\
\hline Хачиа (K) & 3,05 & 3,43 & 3,68 & 3,81 & 3,49 \\
\hline Хиакуме & 3,26 & 3,52 & 3,71 & 3,94 & 3,60 \\
\hline Джиро & 4,07 & 4,21 & 4,33 & 4,45 & 4,26 \\
\hline $\mathrm{HCP}_{05}$ & 0,17 & 0,34 & 0,22 & 0,23 & 0,13 \\
\hline
\end{tabular}

Окружность штамба, см

\begin{tabular}{|l|l|l|l|l|l|}
\hline Хачиа (K) & 24,3 & 32,2 & 34,7 & 35,8 & 31,7 \\
\hline Хиакуме & 23,5 & 28,5 & 30,2 & 30,8 \\
\hline Джиро & 23,4 & 26,3 & 26,8 & 29,3 \\
\hline HCP $_{\mathbf{0 5}}$ & 6,34 & 8,09 & 3,54 & 6,23 & 26,6 \\
\hline
\end{tabular}


Таблица 2. Урожайность сортов хурмы восточной в условиях Дагестана за 2015-2018 годы Table 2. Yield of eastern persimmon varieties in Dagestan for 2015-2018

\begin{tabular}{|c|c|c|c|c|c|}
\hline \multirow{2}{*}{ Варианты } & \multicolumn{5}{|c|}{ Годы исследований } \\
\hline & 2015 & 2016 & 2017 & 2018 & 2015-2018 \\
\hline \multicolumn{6}{|c|}{ Урожайность плодов с дерева, кг } \\
\hline Хачиа (K) & 32,1 & 36,0 & 40,7 & 44,7 & 38,4 \\
\hline Хиакуме & 52,1 & 55,4 & 61,8 & 65,1 & 58,6 \\
\hline Джиро & 26,6 & 29,3 & 34,3 & 37,0 & 31,8 \\
\hline $\mathrm{HCP}_{05}$ & 2,16 & 2,91 & 3,42 & 4,03 & 4,24 \\
\hline \multicolumn{6}{|c|}{ Средняя масса плодов, г } \\
\hline Хачиа (K) & 177,3 & 206,9 & 246,7 & 279,4 & 227,6 \\
\hline Хиакуме & 264,4 & 285,5 & 347,1 & 372,0 & 317,2 \\
\hline Джиро & 135,0 & 154,2 & 194,8 & 218,9 & 175,7 \\
\hline $\mathrm{HCP}_{05}$ & 14,9 & 14,1 & 15,7 & 14,3 & 8,2 \\
\hline \multicolumn{6}{|c|}{ Урожайность, ц/га } \\
\hline Хачиа (K) & 160,6 & 180,4 & 203,6 & 223,4 & 192,0 \\
\hline Хиакуме & 260,4 & 276,9 & 309,1 & 325,6 & 293,0 \\
\hline Джиро & 133,2 & 146,5 & 171,5 & 184,8 & 159,0 \\
\hline $\mathrm{HCP}_{05}$ & 10,8 & 24,4 & 17,1 & 20,1 & 14,9 \\
\hline
\end{tabular}

земной системы деревьев хурмы в зависимости от различных сортов и годов исследований проводили промеры окружности штамба. Данные промеров окружности штамба приведены в таблице 1. Наибольшая прибавка в приросте окружности отмечена у сорта Хачиа (7,4 см). В среднем за 2015-2018 годы она была на 5,1 см больше в сравнении с сортом Джиро.

Высота деревьев у различных сортов хурмы восточной в среднем составила 4,74 м. Диаметр кроны увеличивается в зависимости от возраста. Наибольший показатель диаметра кроны имеет сорт Джиро - 4,26 м, а наименьший - сорт Хачиа (табл.1).

Наилучшие показатели урожайности плодов были получены во всех вариантах опыта в 2018 году. Проведенный анализ показал, по урожайности с дерева сорта Джиро и Хачиа значительно уступают сорту Хиакуме. Урожайность с деревьев этого сорта в наших опытах варьировала по годам и составляла от 52,1 до 65,1 кг с дерева. Полученные данные показали, что и наибольшая урожайность плодов с га в условиях данного опыта наблюдалась у данного сорта - Хиакуме, которая в среднем за три года составила 293,0 ц/га, наименьшая - у сорта Джиро - 159,0 ц/га.

Размеры плодов - сортовой признак и одновременно существенный показатель их товарно-потребительских качеств. Средняя масса плодов хурмы сорта Джиро составила 175,7 г, а максимальная достигала у сорта Хиакуме 317,2 г. В целом, в нашем опыте средняя масса плода по вариантам опыта имела существенные различия (табл.2).

За годы исследований (2015-2018 годы) установлено, что содержание сухого вещества в плодах больше у сорта Хачиа (19,3\%), по сравнению с сортами Хиакуме $(16,4 \%)$ и Джиро (13,8\%) - на 2,9\% и 5,5\% соответственно.

Таблица 3. Биохимическая характеристика плодов различных сортов хурмы восточной в условиях Дагестана за 2015-2018 годы Table 3. Biochemical characteristics of fruits of various varieties of Eastern persimmon in the conditions of Dagestan for 2015-2018

\section{Варианты}

\begin{tabular}{|l|r|}
\hline & $\mathbf{2 0 1}$ \\
\hline Хачиа (K) & 18,6 \\
\hline Хиакуме & 14, \\
\hline Джиро & 12,0 \\
\hline HСР $_{05}$ & 1,38 \\
\hline
\end{tabular}

\section{5}

18,6
14,4
12,0
1,38

\section{Хачиа (K)}

\begin{tabular}{|l|r|}
\hline Хачиа (K) & 12,6 \\
\hline Хиакуме & 11,3 \\
\hline Джиро & 8,2 \\
\hline HCP05 $_{05}$ & 1,35 \\
\hline
\end{tabular}

Хиакуме

Джиро

$\mathrm{HCP}_{05}$

\begin{tabular}{|l|r|}
\hline Хачиа (K) & 12,6 \\
\hline Хиакуме & 11,3 \\
\hline Джиро & 8,2 \\
\hline HCP $_{05}$ & 1,35 \\
\hline
\end{tabular}

Хачиа (K)

Хиакуме

Джиро

$\mathrm{HCP}_{05}$

Годы исследований

\begin{tabular}{|l|l|l|r|}
\hline 2016 & 2017 & 2018 & $2015-2018$ \\
\hline
\end{tabular}

\section{Сухое вещество, \%}

\begin{tabular}{|l|l|l|l|l|}
\hline 19,0 & 19,4 & 20,2 & 19,3 \\
\hline 15,1 & 17,5 & 18,6 & 16,4 \\
\hline 12,6 & 14,9 & 15,7 & 13,8 \\
\hline 1,36 & 1,05 & 0,36 & 0,60 \\
\hline
\end{tabular}

Сумма сахаров, \%

\begin{tabular}{|c|c|c|c|c|}
\hline 6 & 13,0 & 14,3 & 14,5 & 13,6 \\
\hline ,3 & 11,7 & 13,6 & 14,2 & 12,7 \\
\hline 2 & 8,6 & 11,9 & 12,1 & 10,2 \\
\hline 35 & 0,87 & 0,89 & 0,97 & 0,32 \\
\hline & \multicolumn{4}{|c|}{ Содержание витамина С, мг\% } \\
\hline 1 & 45,8 & 46,9 & 49,2 & 46,5 \\
\hline ,8 & 44,0 & 45,9 & 47,5 & 45,3 \\
\hline 4 & 43,4 & 44,5 & 45,3 & 43,9 \\
\hline 4 & 0,99 & 0,75 & 2,72 & 0,41 \\
\hline
\end{tabular}


Значительная часть сухого вещества растворима в воде (сахара, органические кислоты, дубильные вещества, растворимые формы пектиновых, азотистых и минеральных веществ), количественно преобладают водорастворимые сахара.

Содержание витамина С в мякоти плодов хурмы восточной обуславливает пищевую ценность, высокие вкусовые качества, их лечебные свойства. Высоким содержанием витамина C выделяются свежие плоды сорта Хачиа $(46,5$ мг\%), у других сортов меньше - Хиакуме (45,3 мг\%) и Джиро (43,9 мг\%) (табл.3). Колебания по содержанию витамина C по годам связаны с количеством осадков в период вегетации и условиями орошения. Оптимальная влагообеспеченность насаждений способствуют повышению, а засушливые условия - понижению содержания витамина С.

\section{Заключение}

Комплексное изучение биологических признаков деревьев, проведенное нами в 2015-2018 годах, позволяет дать детальную оценку различным сортам хурмы восточ-

\section{Об авторах:}

Рындин А.В. - доктор с.-х. наук, академик РАН, директор ФГБНУ «Всероссийский научно-исследовательский институт цветоводства и субтропических культур» Загиров Н.Г. - доктор с-х. наук, просеессор, главный научный сотрудник отдела субтропических и южНых плодовых культур ФГБНУ ВНИИЦЦ и СК

Ибрагимов Н.А. - кандидат с.-х. наук, внештатный научный сотрудник отдела субтропических и южных плодовых культур ФГБНУ ВНИИЦ и СК

\section{- Литература}

1. Витковский В.Л., Петрова Е.Ф. Изучение коллекции субтропических плодовых культур / Методические указания. - Л.; ВАСХНИЛ. 1989. - 144 с.

2. Габибов Т.Г. Влияние плотности посадки интродуцированных сортов хурмь восточной на урожайность в условиях Южного Дагестана // Садоводство виноградарство. - 2011. - №3. - С.41-45.

3. Гогия В.Т. Биохимия субтропических растений / М. Колос, 1984 - С. 156-165. 3. Загиров Н.Г., Аммайгаджиев Г. К. Казбеков Б.И.: К (1) для развития субтропических плодовых кульр Веном Дагестане // Мат. всерос.научно-практ.конф. "Субтропическое садоводство России и основные направления научного обеспечения его развития до 2010 года». - Сочи. 2004. C. $51-54$.

5. Загиров Н.Г., Аммайгаджиев Г.К., Казбеков Б.И. Геоинформационное моделирование оптимальности размещения субтропического садоводства в ландшафтах Дагестана // Мат. всерос.научно-практ.конф. "Субтропическое садо водство России и основные направления научного обеспечения его развития до 2010 года». - Сочи, 2004. - С.54-56.

6. Загиров Н.Г., Мурсалов М.М., Габибов Т.Г. Рост и развитие интродуцирован ных сортов восточной хурмы в южноравнинной подзоне Дагестана // Мат. всерос.научно-практ.конф. "Образование, наука, инновационный бизнес - сельскому хозяйству регионов». Махачкала. 2007. - С.143-144.

7. Загиров Н.Г., Мурсалов М.М., Габибов Т.Г. О возможности выращивания хурмы восточной в Южном Дагестане // Вестник Российской академии сельскохозяйственных наук. № 3 (июль-август). Москва. - 2010. - С.31-33.

8. Загиров Н.Г., Мурсалов М.М., Габибов Т.Г. Биологические особенности 8. Загиров Н.Г., Мурсалов М.М., Габибов Т.Г. Биологические особенности хурмы и хохяйственная оценка сортов хурмы восточной в Дагестане // Вестник Российской акдем

9. Загиров Н.Г., Габибов Т.Г, Тавлуева М.Б. Биохимическая оценка

плодов интродуцированных сортов хурмы восточной в сухих субтропиках

Южного Дагестана // Субтропическое и декоративное садоводство: сб.науч

тр. / Сочи, ВНИИЦ и СК, 2011. - Вып. 44. - С.115-119.

10. Кобляков В.В. Биологические особенности хурмы и биохимический состав плодов в условиях Прикубанской зоны плодоводства // КубГАУ. - 2007. - Вып. №5(9). - С.85-88.

11. Кобляков В.В., Ченцова Е.С. Перспективы использования видов диоспирус (Diospyros L.) // Материалы междунар.научно-практ. конф. "Субтропическое растениеводство и южное садоводство России»: сб.науч.тр. - Сочи: ВНиИЦ и СК, 2009. - Вып.42. - Т.ІІ. - С.342-346.

12. Методические указания по изучению коллекции субтропических плодовых 12. Методические указания
культур. - Л., $1989 .-144$ с.

культур. - Л., 1989. - 144 с. Агропромиздат, 1988. - С.136-145.

Агропромиздат, 1988. - С. $136-145$.

14. Омаров М.Д, Хурма восточная в субтропиках России. Сочи. 2000. - 98 с.
15. Омаров М.Д., Рындин А.В. Сортимент хурмы восточной в субтропиках России // Материалы межд. Научно-практ.конф. "Субтропическое растение водство и южное садоводство России»: сб.науч.тр. - Сочи: ВНИИЦ и СК, 2009 - Вып.42. - Т.ІІ. - С.332-341.

16. Омаров М.Д., Беседина Т.Д. Возделывание хурмы восточной в субтропиках России: Монография. - Сочи; Всероссийский научно-исследовательский институт цветоводства и субтропических культур Россельхозакадемии, 2011. $162 \mathrm{c.}$

17. Рындин А.В., Омаров М.Д., Загиров Н.Г., Омарова З.М., . Авидзба М.А. Атлас сортов и гибридов хурмы восточной // ВНИИЦ и СК, Сочи - Махачкала Сухум, 2014. - Выпуск І. - 92 с.

18. Омаров М.Д. Продуктивность сортов хурмы восточной в зависимости от 18. Омаров М.Д. Продуктивность сортов хурмы восточной в зависимости от развития деревьев // Субтропическое и декоративное
сб.науч.тр./-Сочи. ВНИиц и СК, 2015. - Вып. 52. - С.67-70.

сб.науч.тр./ -Сочи. ВНИИЦ и СК, 2015. - Вып. 52. - С. 67-70.
19. Программа и методика сортоизучения плодовых, ягодных и орехоплодных культур / Под ред. Е.Н. Седова, Г.П. Огольцовой. - Орел: ВНИИС.П.К, 1999.

608 с. России. М., ИК «Родник», «Аграрная наука», 1997. - 184 с. ной в изменяющихся агроэкологических условиях Южного Дагестана. Исследования показали, что орошение в зоне недостаточного увлажнения в большей степени активизирует ростовые процессы у сортов хурмы. При этом наибольшая высота дерева (4,74 м) и окружность штамба (31,7 см) отмечена в варианте с контрольным сортом Хачиа, а набольший диаметр кроны среди изучаемых сортов хурмы был у сорта Джиро (4,26 м).

Оценка результатов опыта подтверждает достоверность полученных прибавок урожайности по вариантам опыта во все годы исследований. Высокой урожайностью характеризовался сорт Хиакуме - 293,0 ц/га.

Немаловажен химический состав плодов, от которого в совокупности с условиями выращивания зависит их лежкоспособность. Плоды изученных сортов хурмы восточной хорошо транспортабельны, лежкие, высоких потребительских качеств.

Полученные данные свидетельствуют о том, что среди изученных сортов хурмы наибольшим содержанием сухого вещества, суммы сахаров, аскорбиновой кислоты отличился контрольный сорт Хачиа (19,3\%; 13,6\%; 46,5\%).

\section{About the authors:}

Aleksey V. Ryndin - Doctor of Agricultural Sciences, Academician of the Russian Academy of Sciences, Director

Nadir G. Zagirov - Doctor of Agricultural Sciences, Professor, Chief Researcher of the Department of Subtropical and Southern Fruit Crops

Nasir A. Ibragimov - Candidate of Agricultural Sciences, part-time researcher of the subtropical and southern fruit crops department

\section{- References}

1. Vitkovsky V.L., Petrova E.F. Study of the collection of subtropical fruit crops / Methodical instructions. L.; VASKHNIL. 1989. 144 p.

2. Gabibov T.G. Influence of planting density of introduced varieties of eastern persimmon on yield in the conditions of Southern Dagestan // Horticulture and Viticulture. 2011. №3. P.41-45.

3. Gogia V.T. Biochemistry of subtropical plants / M.: Kolos, 1984. P.156-165 4. Zagirov N.G., Ammaigadzhiev G.K., Kazbekov B.I. Agroecological conditions for the development of subtropical fruit crops in South Dagestan // Subtropical horticulture of Russia and the main directions of scientific support for its development until 2010. Sochi, 2004. P.51-54.

for its development until 2010. Sochi, 2004. P.51-54. ing of optimal placement of subtropical gardening in landscapes of Dagestan ing of optimal placement of subtropical gardening in landscapes of Dagestan // Subtropical horticulture of Russia and the main directions
port for its development until 2010. Sochi, 2004. P.54-56.

port for its development until 2010. Sochi, 2004. P.54-56.
6. Zagirov N.G., Mursalov M.M., Gabibov T.G. Growth and development of introduced varieties of eastern persimmon in the southern-leveled subzone of Dagestan // Education, science, innovative business - agriculture of the regions. Makhachkala. 2007. P.143-144.

7. Zagirov N.G., Mursalov M.M., Gabibov T.G. On the possibility of growing eastern persimmon in South Dagestan // Bulletin of the Russian Academy of Agricultural Sciences. Number 3 (July-August). Moscow, 2010. P.31-33.

8. Zagirov N.G., Mursalov M.M., Habibov T.G. Biological features of the persimmon and the hohyaystvennoe assessment of Eastern persimmon varieties in Dagestan. №3 (July-August). Moscow. 2010. P.31-33.

9. Zagirov N.G., Habibov T.G., Tavlueva M.B. Biochemical assessment fruits of 9. Zagirov N.G., Habibov T.G., Tavlueva M.B. Biochemical assessment fruits of
introduced varieties of eastern persimmon in dry subtropics Southern introduced varieties of eastern persimmon in dry subtropics Southern
Dagestan // Subtropical and Ornamental Gardening: collection of scientific Dagestan // Subtropical and Ornamental

10. Koblyakov V.V. Biological features of persimmon and biochemical composition of fruits in the conditions of the Prikubanskaya fruit growing zone // KubSAU, 2007. Vol. No.5 (9). P.85-88

11. Koblyakov V.V., Chentsova E.S. Prospects for the use of species of diospirus (Diospyros L.) // Subtropical plant growing and southern horticulture of Russia: collection of scientific papers. Sochi, 2009. Issue 42. T.II. P.342-346.

12. Guidelines for the study of the collection of subtropical fruit crops. L., 1989. $144 \mathrm{p}$

13. Mikeladze A.D. Subtropical fruit and technical crops. M.: Agropromizdat, 1988. P.136-145

14. Omarov M.D. Eastern Persimmon in the subtropics of Russia. Sochi, 2000 $98 \mathrm{p}$.

15. Omarov M.D., Ryndin A.V. Assortment of Eastern Persimmon in the Subtropics of Russia // Subtropical plant growing and southern horticulture of Russia: Sochi, 2009. Issue 42. T.II. P.332-341.

16. Omarov M.D., Besedina T.D. Cultivation of Eastern persimmon in the subtropics of Russia: -Monography. - Sochi; All-Russian Research Institute of Floriculture and Subtropical Crops of the Russian Agricultural Academy. 2011 $162 \mathrm{p}$.

17. Ryndin A.V., Omarov M.D., Zagirov N.G., Omarova Z.M., Avidzba M.A. Atlas of varieties and hybrids of eastern persimmon // Sochi - Makhachkala Sukhum, 2014. Issue I. $92 \mathrm{p}$.

18. Omarov, M.D. Efficiency of Eastern Persimmon Varieties depending on the development of trees // Subtropical and Ornamental Horticulture: collection of scientific papers / Sochi, 2015. Vol. 52. P.67-70.

19. Program and methods of sorting fruit, berry and nut crops / Ed. E.N. Sedov G

Sedov, G.P. Ogoltsova. Orel, 1999. 608 p.
20. Sapiev A.M., Vorontsov V.V., Koblyakov V.V. Subtropical Horticulture of Russia. M, 1997. $184 \mathrm{p}$. 